\title{
Rice Collectors' Attitude Towards Purchasing of Hybrid Rice in Myanmar
}

\author{
Naing Kyi Win ${ }^{1, ~ *, ~ N y e i n ~ N y e i n ~ H t w e ~}{ }^{2}$, Cho Cho $\mathrm{San}^{3}$, Kyaw Kyaw Win ${ }^{4}$ \\ ${ }^{1}$ Department of Agronomy, Yezin Agricultural University, Nay Pyi Taw, Myanmar \\ ${ }^{2}$ Department of Agricultural Extension, Yezin Agricultural University, Nay Pyi Taw, Myanmar \\ ${ }^{3}$ Department of Agricultural Economics, Yezin Agricultural University, Nay Pyi Taw, Myanmar \\ ${ }^{4}$ Yezin Agricultural University, Nay Pyi Taw, Myanmar
}

\section{Email address:}

naingkyiwinwin9@gmail.com (N.K. Win), nyeinnyeinhtwe@yau.edu.mm (N. N. Htwe), dr.chochosan@yaummr.org (C. C. San), Drkkwinagro@gmail.com (K. K. Win)

${ }^{*}$ Corresponding author

\section{To cite this article:}

Naing Kyi Win, Nyein Nyein Htwe, Cho Cho San, Kyaw Kyaw Win. Rice Collectors' Attitude Towards Purchasing of Hybrid Rice in Myanmar. American Journal of Agriculture and Forestry. Vol. 7, No. 1, 2019, pp. 28-35. doi: 10.11648/j.ajaf.20190701.15

Received: January 23, 2019; Accepted: March 11, 2019; Published: March 27, 2019

\begin{abstract}
Hybrid rice is one of the most feasible options for increasing rice reproduction and Myanmar has area expansion under hybrid rice production. However, hybrid rice is a very new seed industry but social perceptions are not favorable. The objectives of the study were: 1) to study the characteristics of the rice collectors and their performance on purchasing of hybrid rice, 2) to identify the determinants for changing attitudes of willing to purchase by rice collectors. The study was conducted in Nay Pyi Taw area, Myanmar and used structured questionnaires to collect data from 61rice collectors. Data was analyzed by using descriptive statistics and Likert-type scale. This study revealed that majority $75.4 \%$ of respondents were rice brokers and $24.6 \%$ of them were miller collectors. Then, $82.0 \%$ out of respondents were male and respondents' average age was 49 years. Next, $72.4 \%$ of rice collectors had formal education and $27.9 \%$ rice collectors possessed Bachelor degree. Besides, more than half $52.5 \%$ of rice collectors were above 10 years buying experience. Majority $91.8 \%$ of rice collectors bought above 836 tons in monsoon and over 2090 tons in summer paddy. Moreover, 63.9\% of collectors received information to purchase from "hybrid rice seed companies", less than half of respondents received information from "extension workers", from "contract farming, from "fellow buyers" and accepted the information of "price less than local varieties", those points were mentioned as "very important or important". In addition, majority $82 \%$ of rice collectors stated "strongly agreed" or "agree" to the point of "need to grow hybrid rice for rice industry development", more than half $65.5 \%$ of respondents expressed strongly agree or agree to the point of "hybrid rice is more profitable than inbred rice", $86.9 \%$ of respondents mentioned strongly agree or agree to the point of "enhancing quality of hybrid rice varieties", $70.5 \%$ of respondents pointed out to "more milling outcome and avoid chalkiness", $85.3 \%$ of respondents strongly agree or agree to "hybrid rice definitely advantages of outputs and export easily" and $85.2 \%$ of rice collectors expressed strongly agree or agree to the point of "I am willing to pay extra money if it is good in quality. Overall results of this study, rice collectors have desired to buy the unique paddy rice grain shape, color, chalkiness, white belly, and milling performance of grain translucency that drive the price and their decision for purchasing. This study highlighted the areas needed to improve such as establishment of a well-structured research programs to develop new consumers' preferable hybrid rice varieties, public ICT system for agriculture, and advertising campaign persuaded by extension services and communication channels, marketing system and quality seed control system.
\end{abstract}

Keywords: Attitude, Rice Collectors, Purchasing, Hybrid Rice

\section{Introduction}

This study was an integral part of the whole research of hybrid rice supply change and influential attitudes of rice collector's willingness to purchase hybrid rice and their perceptive to develop hybrid rice technology. 
DOA (2017) mention that in Myanmar total rice growing area was 7 million hectare, over 29.26 million tons of production and yield of 3.84 ton/ha in 2016-17 growing season [1]. IRRI (2017) reported rice is the staple food and main energy source of the Myanmar people. Rice consumption per capita is approximately 154 kilograms per year [2]. Denning et al (2003) reported Myanmar consumers are sensitive to eating depend on quality. People prefer the rice which is not soft and hard after cooking. Besides, there are two components to seed selection: choice of variety and quality of seed. The choice of variety is made by farmers based on: (1) adaptation to the growing environment, (2) eating/cooking preferences of the consumers, (3) market preference/price, and (4) cost of seed. Modern rice varieties (also known as HYVs) are variously reported to be used for $70-80 \%$ of the monsoon crop and for virtually all summer crops [3].

IRRI (1997) showed in Hybrid Rice Breeding Manual; hybrid rice has the potential of yielding $15-20 \%$ more than that of best inbred varieties grown under similar conditions [4]. DOA (2015) reported in Myanmar, hybrid rice cultivation was commercially initiated again in 2011, monsoon season and increased areas year by year up to $2.1 \%$ of total rice growing area. Besides, it could be successful 10 ton/ha (potential yield) if it had systematic and proper care and consequently resulting in alleviating of poverty and better living standard of Myanmar farmers. There is changing variety for superior output production, it is needed to choose for hybrid rice production in Myanmar [5].

In Myanmar, rice is generally collected by wholesalers and wholesalers contact to collectors and brokers who typically collect paddy, directly from farmers in small scale but in some regions famers directly sell their paddy go to the wholesalers or to the millers. Some wholesalers themselves are rice millers, some resell the purchased paddy to the rice millers. Rice millers delivered to retailer for the domestic consumption and exporters for international markets. Some wholesalers purchase rice from main regions and sell to retailers. Some exporting companies themselves are millers and wholesalers and they also purchase large amount, milled rice according to the grades and then export, the involvement of private sectors in milling, trading and processing also solves the problem of existing multi-layer and compacted distribution system that cause inefficiency in the marketing system. According to Nay (2012) mentioned in his paper that farmers are selling after harvest, directly to the millers without or reducing the use of brokers and local traders in some township. This is increasing return for farmers. This makes it difficult for Myanmar to ensure a stable position on the international market, and there is no consistent business flow from the producers through collectors to consumers/export [6]. MRF (1014) showed that the private sector composed of farmers, input suppliers, traders, millers, processors, and exporters, drive the extensive rice value chain. Individual entrepreneurs to large wholesalers and exporters are involved in production, collection, processing, marketing, and distribution [7].

Hazra (2001) supported grain shape and appearance, milling and head rice recovery, amylose content and gelatinization temperature (alkaline value) are some of the parameters that influence the cooking and eating qualities of rice. All hybrids released, including those marketed by the private sector, were evaluated for quality traits. A good quality hybrid has:1) head rice recovery of over $55 \%$; 2) intermediate amylose content $(20-25 \%) ; 3)$ intermediate alkaline value (4.0-5.0); and 4) translucent grains without chalkiness [8].

Therefore, rice collectors evaluated for quality characteristics of hybrids before purchasing rice which is used almost exclusively as a food product. Cooking and eating quality traits therefore assume special significance. For general, consumer acceptance is essential that the hybrids developed good quality traits as well as high yielding potential Therefore, the hybrids included in development of parental lines have been critically screened for various quality parameters. Preferences for quality vary from region to region. A variety of hybrid liked in one region may not be liked in another. Therefore, it is imperative to bear in mind local preference when developing hybrids.

Smith (1982) mentioned that attitudes are related to how people perceive the situations in which they find themselves. Also, attitudes vary in direction (either positive or negative), in degree (the amount of positiveness or negativeness), and in intensity (die amount of commitment with which a position is held, [9]. Smith and Ragan (1999) expressed the role of prior attitudes is in shaping attitude formation and change. They describe attitude as a kind of spectrum with "latitude of acceptance" surrounding a current attitude; a new position is more likely to be accepted if it falls within this latitude and less likely to be accepted if it does not [10].

Farmer complained to grow hybrid rice due to the market problem, low grain price and poor eating quality. On the other hand, rice collectors' attitudes to buy or collect hybrid rice grain according to their preferable characters and collect from farmers. Therefore, study objectives were as follows;

(1) to study the characteristics of the rice collectors and their performance on purchasing of hybrid rice,

(2) to identify the determinants for changing attitudes of willing to purchase by rice collectors

Hybrid rice cultivation and production in Study area

DOA (2016/17) reported that in Nay Pyi Taw area, rice has been grown two-times per year as monsoon rice and summer rice by farmers who were growing hybrid rice and inbred rice. Therefore, rice collectors have bought the inbred rice and also hybrid rice. There was (53876) total rice growing farmers representing (66266) hectares in Nay Pyi Taw area, in 2016-17. Out of which (51597) farmers were inbred rice growing farmers and (2279) farmers were hybrid rice growing farmers. Table 1 reported that there were grown maximum (5197) hectares in 2014-15 year but it was going down the cultivated area and also production, [11]. It was commonly grown hybrid rice varieties such as GW1, Long 8, Long 10 and Long 12, characteristics of these hybrid rice varieties were particularly translucent, low amylose and good eating quality, local people was not prefer due to so soft and chalkiness of rice although it has potential to get more milling outcome. On the other hand, local inbred rice varieties were Manathukha, Sinthukha, Thainankauk and 
Ayeyarmin which were usually collected by rice collectors whenever farmers sell to those varieties, Table 2 .

Table 1. Situation of hybrid rice and inbred rice cultivation and production.

\begin{tabular}{lllll}
\hline \multirow{2}{*}{ Year } & Hybrid rice & & Inbred rice & \\
\cline { 2 - 5 } & Sown (hectare) & Production(ton) & Sown -(hectare) & Production(ton) \\
\hline $2011-2012$ & 1059 & 17684 & 73900 & 810602 \\
$2012-2013$ & 2335 & 38447 & 68378 & 741720 \\
$2013-2014$ & 3355 & 55496 & 70712 & 771078 \\
$2014-2015$ & 7197 & 83789 & 67311 & 740350 \\
$2015-2016$ & 4901 & 78748 & 66788 & 732142 \\
$2016-2017$ & 1845 & 27075 & 73098 & 80014 \\
\hline
\end{tabular}

Source: DOA, Nay Pyi Taw

Table 2. Characteristics of rice varieties mostly grown in Nay Pyi Taw area.

\begin{tabular}{llllll}
\hline Varietal Name & Growth duration & Grain appearance & Milling outcome & Amylose content & Eating quality \\
\hline Hybrid rice & & & & & \\
GW1 & $105-110$ & Long grain/chalkiness & 70.0 & 22.0 & Good \\
Long 8 & $110-120$ & Translucent & 69.5 & 22.4 & Good \\
Long 10 & $115-125$ & Translucent & 73.0 & 20.0 & Good \\
Long 12 & $110-120$ & Translucent & 72.0 & 18.0 & Good \\
Inbred rice & & & & \\
Sinthukha & $140-145$ & Translucent & 60.5 & 25.08 & Not bad \\
Manawthukha & $135-140$ & Translucent & 63 & 28.0 & Good \\
Ayeyarmin & $140-145$ & Translucent & 60 & 26.23 & Soft and good \\
Thainankuak & $110-115$ & Translucent & 54 & 20.09 & medium \\
\hline
\end{tabular}

Source: DOA (Nay Pyi Taw) and DAR (Department of Agricultural Research)

Table 3. Estimated purchase amount of Rice collectors in Nay Pyi Taw area.

\begin{tabular}{lllll}
\hline \multirow{2}{*}{ Township } & \multicolumn{2}{l}{ Estimated purchasing amount (ton) } & & Totalrice collectors \\
\cline { 2 - 5 } & Above 313 & Above 253 & Above 836 & 10 \\
\hline Dekkhinathiri & 8 & 2 & 0 & 14 \\
Lewe & 1 & 10 & 3 & 15 \\
Pyinmana & 3 & 9 & 3 & 11 \\
Zabuthiri & 0 & 10 & 1 & 2 \\
Ottarathiri & 0 & 2 & 0 & 2 \\
Pobbathiri & 0 & 1 & 1 & 102 \\
Tatkone & 0 & 102 & 0 & 6 \\
Zeyarthiri & 0 & 4 & 2 & 162 \\
Total & 12 & 140 & 10 & \\
\hline
\end{tabular}

Source: DOA (Nay Pyi Taw) and Department of Trade and Commerce

\section{Research Methodology}

Study was conducted at Nay Pyi Taw area including Pyinmana, Lewe, Dekhinathiri, Zabuthiri, Tatkone, Pobbathiri, Zeyarthiri, and Ottarathiri Townships. Data was collected from Rice Miller Association and DOA Township officers' offices, Table 3 was Sixteen one rice collectors were randomly selected and collected the information in the survey which covered features of collectors such brokers and miller collectors were interviewed by using quaternaries between August to September, 2018.The collected data were demographic factors, purchasing experience and buying amount of rice, preferable type of rice, information sources, market situation, rice collectors' opinion on hybrid rice, and rice collectors' attitude to change to hybrid rice, determinants and their future perception to buy hybrid rice.

Hogg and Vaughan (2005) pointed out that an attitude is "a relatively enduring organization of beliefs, feelings, and behavioral tendencies towards socially significant objects, groups, events or symbols" [12]. McLeod (2018) expressed that attitudes can serve functions for the individual as "Attitudes and behavior", [13]. Katz (1960) showed that outlines of four functional areas: The knowledge function is our need for a world which is consistent and relatively stable. This allows us to predict what is likely to happen, and so gives us a sense of control. Attitudes can help us organize and structure our experience, knowing a person's attitude helps us predict their behavior. Self / Ego-expressive function: The attitudes we express (1) help communicate who we are and (2) may make us feel good because we have asserted our identity. Self-expression of attitudes can be nonverbal too: Therefore, our attitudes are part of our identity and help us to be aware through the expression of our feelings, beliefs and values. Adaptive function: If a person holds and/or expresses socially acceptable attitudes, other people will reward them with approval and social acceptance. The ego-defensive function: attitudes that protect our self-esteem or that justify actions that make us feel guilty. The basic idea behind the functional approach is that attitudes help a person to mediate between 
their own inner needs (expression, defense) and the outside world (adaptive and knowledge). The basic idea behind the functional approach is that attitudes help a person to mediate between their own inner needs (expression, defense) and the outside world (adaptive and knowledge), [14].

In order to achieve the objectives, it was analyzed by simple descriptive and Likert scale to measure attitude [15]. The typical Likert scale includes a 5-7 point ordinal scale to rate the degree to which they agree or disagree with the statement by respondents. Data were ascertained utilizing a five-point "Likert-type" scale concerning one to five levels of "agreement": 1) "Strongly agree", 2) "Aagree",3) "Neutral”) "Disagree" and d) "Strongly disagree".

\section{Results and Discussion}

\subsection{Demographic Profile of Rice Collectors}

In this study found out that two third of $75.4 \%$ of rice collectors were rice brokers and $24.6 \%$ of them were miller collectors. Majority $82.0 \%$ of respondents were male rice collectors and $18.0 \%$ of them were female rice collectors. Next, their average age was 49 years, ranging from a minimum of 30 years to a maximum age of 68 years. More than half $54.1 \%$ of rice collectors were under high school, $27.9 \%$ rice collectors possessed Bachelor Degree and a few $18.0 \%$ of rice collectors finished the high school. Besides, regarding the rice buying experience; $23.0 \%$ of respondents had 1 to 5 years buying experience and $24.6 \%$ of respondents had 6 to 10 years, while $8.2 \%$ of rice collectors had 11 to 15 years and $23.0 \%$ of rice collectors had 16 to 20 years and the remaining of $21.3 \%$ of rice collectors had above 21 years experiences. Moreover, majority $91.8 \%$ of rice collectors bought above 836 tons in monsoon and over 2090 tons in summer paddy, 3.3\% of small collectors purchased $105-314$ tons and $1.6 \%$ of rice collectors collected 315 to 627 tons, while $3.3 \%$ of collectors bought 628 to 836 tons yearly, (Table 4).

\subsection{Important Information Sources of Rice Collectors}

This study revealed that rice collectors connected to information sources for purchasing of rice fromfarmers. A few $3.3 \%$ and $16.4 \%$ of rice collectors showed 'very important and important' information source to "Farmer Economic Journal", while $32.8 \%$ and $41.0 \%$ of rice collectors mentioned less important and not important, $6.6 \%$ of rice collector did not know to this Journals. Next, rice collectors made friendship with extension agents who give the information to buy rice. Therefore, rice collectors were supported the information by "extension workers" that a few $(6.6 \%)$ and $36.1 \%$ of rice collectors appreciated to extension agents who expressed "very important" and important, but $19.7 \%$ and $32.8 \%$ of rice collectors mentioned less important and not important, while $4.9 \%$ of rice collectors did not gain to access to extension agents. Besides, information from "hybrid rice seed Co., Ltds" to buy hybrid rice; most $42.6 \%$ and $21.3 \%$ of rice collators answered "very important, and important, while $26.2 \%$ and $4.9 \%$ of rice collectors demonstrated less important and not important, a few $4.9 \%$ of rice collectors did not communicate to seed companies.

Table 4. Demographic profiles of rice collectors.

\begin{tabular}{lll}
\hline Demographic variables & Frequency & Percent \\
\hline Rice collectors & & \\
Brokers & 46 & 75.4 \\
Miller Collectors & 15 & 24.6 \\
Age (Year) & & \\
$21-30$ & 4 & 6.6 \\
$31-40$ & 7 & 11.5 \\
$41-50$ & 29 & 47.5 \\
$51-60$ & 16 & 26.2 \\
Above 60 & 5 & 8.2 \\
Gender & & \\
Male & 50 & 82.0 \\
Female & 11 & 18.0 \\
Level of Education & & \\
Under high school & 33 & 54.1 \\
High school & 11 & 18.0 \\
Bachelor Degree & 17 & 27.9 \\
Year of buying Rice & & \\
1 to 5 & 14 & 23.0 \\
6 to 10 & 15 & 24.6 \\
11 to 15 & 5 & 8.2 \\
16 to 20 & 14 & 23.0 \\
Above 21 & 13 & 21.3 \\
Buying (Ton) & 2 & 3.3 \\
105-314 & 56 & 91.8 \\
315-627 & & \\
$628-836$ & & \\
Above 836 & & \\
\hline & & \\
\hline
\end{tabular}

$(\mathrm{n}=61)$

Moreover, Seed Co.,Ltds engaged rice contract farming with farmers. It was found out the information of rice purchasing from "contract farming"; $19.7 \%$ and $24.6 \%$ of collectors mentioned very important and important but $27.9 \%$ and $19.7 \%$ of rice collectors showed less important and not important, while $8.2 \%$ of rice collectors did not notice to contact farming practice. In addition, information from "fellow rice collectors"; almost $14.8 \%$ and $23.0 \%$ of collectors indicated very important and important, while $31.1 \%$ and $23.0 \%$ of collectors showed less important and not important, $8.2 \%$ of collectors directly bought from farmers. A few $6.6 \%$ and $1.6 \%$ of collectors disclosed very important and important, however more than half $54.1 \%$ of rice collectors responded less important and $39.3 \%$ of rice collectors responded not important to the point "market information" and $4.9 \%$ of collectors normally bought rice harvesting season. Furthermore, a few $6.6 \%$ and $8.2 \%$ of rice collectors mentioned very important and important to export market available, on the other hand, more than half $54.1 \%$ of collectors and $18.0 \%$ collectors declared not important, while $13.1 \%$ of rice buyers explained that this is their seasonal work so they were far away from export markets. Initially, rice collectors had opinion likely to buy hybrid rice the information was "price less than inbred rice"; almost $31.1 \%$ and $16.4 \%$ of collectors preferred to show very important and important but $16.4 \%$ and $21.3 \%$ of rice collectors mentioned less important and not important, while $14.8 \%$ of rice collectors did not mention because rice price was depend on the quality they responded (Table 5). 
Table 5. Important information sources for rice collectors.

\begin{tabular}{|c|c|c|c|c|c|c|c|c|c|c|}
\hline \multirow{2}{*}{ Information source } & \multicolumn{2}{|c|}{ Very Important } & \multicolumn{2}{|c|}{ Important } & \multicolumn{2}{|c|}{ Neutral } & \multicolumn{2}{|c|}{ Less Important } & \multicolumn{2}{|c|}{ Not Important } \\
\hline & No & $\%$ & No & $\%$ & No & $\%$ & No & $\%$ & No & $\%$ \\
\hline Farmers Economic Journal & 2 & 3.3 & 10 & 16.4 & 4 & 6.6 & 20 & 32.8 & 25 & 41.0 \\
\hline Extension workers & 4 & 6.6 & 22 & 36.1 & 3 & 4.9 & 12 & 19.7 & 20 & 32.8 \\
\hline Hybrid riceSeed Co.,Ltds. & 26 & 42.6 & 13 & 21.3 & 3 & 4.9 & 16 & 26.2 & 3 & 4.9 \\
\hline From contract farming & 12 & 19.7 & 15 & 24.6 & 5 & 8.2 & 17 & 27.9 & 12 & 19.7 \\
\hline Fellow rice collectors & 9 & 14.8 & 14 & 23.0 & 5 & 8.2 & 19 & 31.1 & 14 & 23.0 \\
\hline Export market available & 4 & 6.6 & 5 & 8.2 & 8 & 13.1 & 33 & 54.1 & 11 & 18.0 \\
\hline Price less than inbred variety & 19 & 31.1 & 10 & 16.4 & 9 & 14.8 & 10 & 16.4 & 13 & 21.3 \\
\hline
\end{tabular}

$(\mathrm{n}=61)$

\subsection{Rice Collectors' Preferable Characters of Hybrid Rice to Buy from Farmers}

Table 6 indicated that $68.85 \%$ of collectors preferred to buy long grain rice, fragrant and good eating quality. Then $29.51 \%$ of respondents wished to buy normal moisture when they were buying and half of $50.81 \%$ of rice collectors selected to buy good grain color rice. Some rice collectors reported their opinion on willingness to purchase was depends on local markets or export potential. Some of them intended to buy hybrid rice to export china market. Local consumers appreciated that hybrid rice namely Long 8 and GW1 around after 6.-8 months stored, hybrid rice paddy grains were accepted to eat and upland people likely to eat mostly because they were pleased to have softening of cooked rice. Therefore, some collectors send the milled hybrid rice to hilly regions. As a result, hybrid rice grains begin acceptable to buy among the rice collectors.

Table 6. Collectors' preferable characters of rice to buy rice from farmers.

\begin{tabular}{lll}
\hline Statement & Frequency & Percent \\
\hline Long grain and fragrant & 42 & 68.85 \\
Good eating quality & 42 & 68.85 \\
Normal moisture content & 18 & 29.51 \\
Good in color & 31 & 50.81 \\
\hline
\end{tabular}

\subsection{Rice Collectors'Attitudes to Hybrid Rice Development}

This study revealed that majority $82 \%$ of rice collectors showed "strongly agree" or "agree" to the point of "grow more hybrid rice for rice industry development", but (11.5\%) were "disagree" and no one showed "strongly disagree", while $(6.5 \%)$ of respondents did not know hybrid rice was important or unimportant for rice industry. Next, more than half $65.6 \%$ of respondents showed "strongly agree" or "agreed" to the point of "hybrid rice is more profitable than local varieties" and almost $31.2 \%$ of respondents answered "disagree" or "strongly disagree", the remaining (3.3\%) of rice collectors did not mention to this point. Besides, half of $(50.8 \%)$ of respondents expressed "strongly agree" or "agree", but $36.1 \%$ and $6.6 \%$ of rice collectors responded "disagree" and "strongly disagree", while $(6.6 \%)$ of respondents did not mention to the point of "I always pay price more than inbred rice price". In addition, majority $86.9 \%$ of respondents were "strongly agree or agreed to that point of "enhancing quality of hybrid rice", while $1.6 \%$ and $3.3 \%$, of respondents showed "disagree and strongly disagree" to that point. Most of 70.5\% of the respondents answered strongly agree or agree to point of" more milling outcome and avoid chalkiness", $24.6 \%$ of rice collectors showed strongly disagree or disagree and $4.9 \%$ rice collectors did not remark to this point. Rice collectors' attitude to point of "Hybrid rice is normally less management of post harvest time"; $52.5 \%$ of rice collectors indicated strongly agree or agree, $40.9 \%$ of rice collectors reported strongly disagree or disagree and $6.6 \%$ of rice collectors did not mention their opinion. In regard to "hybrid rice is less labor used than inbred rice when buying"; $29.5 \%$ of rice collectors remarked strongly agree or agree, more than half $63.8 \%$ of rice collectors commented to strongly disagree or disagree, while a few $6.6 \%$ of respondents did not respond to this point. Furthermore, majority $85.3 \%$ of respondents were "strongly agree or agreed" to the point of "hybrid rice definitely advantage of output than local rice and export easily" and a few $(6.6 \%)$ of respondents mentioned "disagree", while $(8.2 \%)$ did not mention respectively. Lastly, regarding the point of "I am willing to pay extra money if I know it is good in quality", out of $85.2 \%$ of rice collectors stated strongly agree or agree, while $(1.6 \%)$ and $(11.5 \%)$ of respondents expressed strongly disagree and disagree, remaining of $(1.6 \%)$ did not show their opinion, Table 7.

\subsection{Addition Information}

Rice collector reported that they preferred to buy the hybrid rice varieties of long and slender grain type, bright yellow color and good eating quality. As a result, Department of Agricultural Research (DAR) and other Research Institutions needto develop these types of rice varieties from breeding programs. Besides, Seed Co.,Ltds also produce seeds which persuades the farmers and consumers. Rice collectors reported that the additional information as good seed quality and color, recommended fertilizers rate for hybrid rice, resistance varieties and adaptable to weather condition, increase productivity and export market availability, standard weight, prohibit growing mixed $\mathrm{F}_{1}$ and $\mathrm{F}_{2}$ seed. Nevertheless, farmers' choices were important and stable market is more important for development of hybrid rice. 
Table 7. Rice collectors' attitudes to hybrid rice development.

\begin{tabular}{|c|c|c|c|c|c|c|c|c|c|c|}
\hline \multirow{2}{*}{ Statement } & \multicolumn{2}{|c|}{ Strongly agree } & \multicolumn{2}{|c|}{ Agree } & \multicolumn{2}{|c|}{ Neural } & \multicolumn{2}{|c|}{ Disagree } & \multicolumn{2}{|c|}{ Strongly Disagree } \\
\hline & No & $\%$ & No & $\%$ & No & $\%$ & No & $\%$ & No & $\%$ \\
\hline Need to grow hybrid rice more for rice industry development & 13 & 21.3 & 37 & 60.7 & 4 & 6.6 & 7 & 11.5 & 0 & 0 \\
\hline Hybrid rice is more profitable than local & 8 & 13.1 & 32 & 52.5 & 2 & 3.3 & 17 & 27.9 & 2 & 3.3 \\
\hline I always pay price more than inbred rice price & 5 & 8.2 & 26 & 42.6 & 4 & 6.6 & 22 & 36.1 & 4 & 6.6 \\
\hline Enhancing quality of hybrid rice varieties & 10 & 16.4 & 43 & 70.5 & 5 & 8.2 & 1 & 1.6 & 2 & 3.3 \\
\hline More milling outcome and avoid chalkiness & 8 & 13.1 & 35 & 57.4 & 3 & 4.9 & 14 & 23.0 & 1 & 1.6 \\
\hline Hybrid rice normally less management of post harvest time & 4 & 6.6 & 28 & 45.9 & 4 & 6.6 & 19 & 31.1 & 6 & 9.8 \\
\hline $\begin{array}{l}\text { Hybrid rice is definitely advantages of outputs than local rice } \\
\text { and export easily }\end{array}$ & 15 & 24.6 & 37 & 60.7 & 5 & 8.2 & 4 & 6.6 & 0 & 0 \\
\hline I am willing to pay extra money if I know it is good in quality & 16 & 26.2 & 36 & 59 & 1 & 1.6 & 7 & 11.5 & 1 & 1.6 \\
\hline
\end{tabular}

$(\mathrm{n}=61)$

On the other hand, this study indicated that rice collectors explained why they were not to buy the hybrid rice because of farmers did not grow their buying area so they have not chance to buy. They reported that a few farmers grew $F_{2}$ and some grew mixed $F_{1}$ seeds and $F_{2}$. Therefore, they were afraid of inadequate purity of rice. Moreover, rice collector pointed out their perceptions that farmers faced the problem such as labors investment, and cost which were more needed for hybrid. So far, farmers need credit to supports more and knowledge for systematic cultivation, method demonstration through contact farmers. High price of hybrid seed, poor seed quality were also reasons for unwillingness to buy hybrid rice seeds seasonally. Due to susceptible to pests and diseases of hybrid rice, farmers want to get resistant varieties to solve these problems. In addition, farmers need medium duration varieties for monsoon and some farmers need short duration varieties with high yield for summer season.

MRF (2014) reported that the current loan program of the Myanmar Agricultural Development Bank (MADB) for rice farmers allows them to borrow $250 \$ /$ ha and provides credit for six months only. Their access to additional financing is also very limited. This means that farmers have to sell their entire rice stock immediately after harvesting when the prices are at their lowest to repay their debts [7].

Besides, Seed Co.,Ltds produced hybrid varieties such as long 8 and long 10 and long 12 and GW1. Therefore, these will be needed to check for adequate purity before delivering seeds to farmers. This means, there are seed law enacted but weak in implementation so there is need to more solve to inadequate seed purity and related problems.

Ginigaddara et al, (2017) indicated that eating quality related factors and nutritional factors are the most important factors predicting consumer preference towards consuming traditional rice. Other important factors are marketing factors and cooking quality related factors. Further, it was found that awareness on traditional rice is the main factor influencing on deciding to purchase of traditional rice. Urban consumers purchase traditional rice more compared to rural consumers. When consumer is educated, there is a higher purchasing decision making power than a non-educated consumer. Overall results imply that traditional rice has a good perception in general among rice consumers in Kegalle district in Sri Lanka, [16].
Spielman et al, (2013) supported that although hybrid rice has immense potential for increasing productivity and improving overall welfare for the poor in India, the challenges are not insignificant. Important challenges include increasing both seed and grain quality and customizing varieties to various agro ecological conditions and consumer preferences. Addressing the challenges of grain quality and customizing hybrids to consumer preferences have important implications for the output prices that farmers receive for their grains. At present, the price penalty on hybrid rice at the farm gate places it at $10-20 \%$ less than coarse grain rice in India. Although breeders have made progress in customizing hybrids to consumers' preferences, the new hybrids coming on the market will need to overcome this price penalty to encourage adoption, [17].

Uddin (2014) reported that the market price of hybrid rice grain has not yet gained its positive impact in comparison to inbred rice grain. General consumers in Bangladesh preferred long slender grains with high amylose percent and better cooking and keeping quality. Local OP variety, due to superior taste, gives higher market price compared to hybrids, [18].

Akhter et al, (2004) mentioned in his report that hybrids imported so far are of inferior grain quality that is unacceptable for farmers due to lower prices in local and international market, [19].

Sivagnanam (2004) found out that demand for the hybrid rice is relatively low in the market and they discourage these varieties by offering low price. Lower price is the major challenge the farmers are facing in selling the hybrid variety. The other perceptions prevailing about the hybrid varieties include lack of consumer demand for these varieties, poor cooking and preservation and getting broken during the milling stage, [20].

\section{Conclusion and Recommendation}

This study revealed that rice collectors pleased to buy good eating quality, good color, and long grain and fragrant. Then, this study resulted positively agreed the sources of information to collect the rice were from "extension workers", "hybrid rice seed Co.,Ltds" and "contracted farming". Next, this study highlight that rice collectors' attitudes to hybrid rice development related factors positively agreed to; "farmers 
need to grow hybrid rice more for rice industry development" and "hybrid rice is more profitable than inbred rice". Besides, they want to do "I always pay price more than inbred rice price" and positively pointed to "enhancing quality of hybrid rice varieties", should get "milling outcome than inbred and avoid the chalkiness and white bally". Moreover, some farmers also granted the hybrid rice normally "less management of post harvest time and labor less than inbred rice when buying". In addition, they positively perceived that hybrid rice is definitely "advantages of outputs than inbred rice and export easily" and they want to "pay extra money if they know it is good in quality". Overall results of this study highlighted that, rice collectors have desired to buy the unique paddy rice grain shape, color, chalkiness, white belly, and mill performance of grain translucency that drive the price and their decisions for purchasing.

Recommendations for the development of hybrid rice are as follows;

1. Hybrid rice researchers should prioritize to conduct research of resistant to pest, diseases and evaluation of good eating of the hybrid rice varieties and should be encouraged and prove those values are high in hybrid rice varieties, it is vital to popularize it. Fragrant value added hybrid for market persuasion such as Basmati hybrid rice.

2. Government consider again the credit program for farmers to store long time when price growing up, to get more profits.

3. A public information dissemination system on proven benefits of hybrid rice varieties should be established an advertising campaign should be carried out by using extension and communication channels.

4. Marketing activity should be well structured and regularly monitored by an authorized institute which supplies labels and certification. The capacity of the private sector to effectively and successfully compete in the international rice market therefore it is needs to be improved by laid down short- and long-term strategies.

5. Stringent rules and regulations should be imposed to prevent mixing with inbred rice and also inadequate seed quality.

\section{Acknowledgements}

Authors appreciate the willingness of rice collector, buyers and miller collectors for sharing their attitudes and knowledge concerning rice purchasing experiences and their preference. We also would like to acknowledge the support of staffs from the Department of Agriculture (DOA) and Rice Miller Association, Nay Pyi Taw, for providing their time to assist in data collection.

\section{References}

[1] DOA; Statistical Year Books, Rice Division, Department of Agriculture, Ministry of Agriculture, Livestock and Irrigation, Nay Pyi Taw, Myanmar; 2017.
[2] IRRI; Rice: The pulse of life in Myanmar. Rice Today, International Rice Research Institute, 16 (2), 14; (2017).

[3] G. Denning, K., Baroang and T. M. Sandar, Rice Productivity Improvement in Myanmar, Background Paper No. 2, USAID with Michigan State University (MSU) and MDRI, 2013.

[4] IRRI; Hybrid Rice Breeding Manual, HR2-01. International Rice Research Institute, Los Baños, Laguna, Philippines; 1997.

[5] DOA; Annual Report of Statistic Year Book, Department of Agriculture, Ministry of Agriculture and Irrigation, (MOAI) Nay Pyi Taw, Myanmar; 2015.

[6] N. M. Aung; Production and Economic Efficiency of Farmers and Millers in Myanmar Rice Industry. V. R. F series, No 471. Institute of Developing Economics Japan External Trade Organization; 2012.

[7] MRF; Myanmar Rice Federation. http: //myanmarricefederation. org/ content/about-Myanmar-rice-federation-mrf; 2014.

[8] C., R. Hazra (2001). "Status of hybrid rice development in India". Part three: Countries' experiences in hybrid rice. Proceedings of the workshop on policy support for rapid adoption of hybrid rice on large-scale production in Asia Hanoi, Viet Nam, 22-23 May 2001. Food and Agricultural Organization of United Nations Rome, 2002.

[9] M. J. Smith (1982) Persuasion and human action. Belmont, CA: Wadsworth.

[10] P. Smith, and T. J. Ragan (1999). Instructional design. New York: John Wiley and Sons.

[11] DOA; Statistical Year Books, Rice Division, Department of Agriculture, Ministry of Agriculture, Livestock and Irrigation, Nay Pyi Taw, Myanmar; 2012.

[12] M. Hogg, and G. Vaughan, (2005). Social Psychology (4th edition).London: Prentice-Hall.

[13] S. A. McLeod, (2018). Attitudes and behavior. Retrieved from https: //www.Simplypsychology.org/attitudes.html.

[14] D. Katz (1960). Public opinion quarterly, 24, 163 - 204.

[15] Likert, R. "A Technique for the Measurement of Attitudes." Archives of Psychology 22 (140): 55. 1932.

[16] G. A. S. Ginigaddara, J. P. S. N. Madushika, A. M. K. R. Bandara, and S. P. Dissanayaka, (2017). Purchasing decision making and consumer preference for traditional rice in Sri Lanka: A case study in Kegalle district, international Journal of Advanced Scientific Research and Management, Vol. 2 Issue 4, Apr 2017.

[17] David J. Spielman, Deepthi E. Kolady and Patrick S. Ward "The prospects for hybrid rice in India" Food Sec. DOI 10. 1007/s12571-013-0291-7. Springer Science+Business Media Dordrecht and International Society for Plant Pathology 2013.

[18] A. Uddin (2004). "Hybrid rice development in Bangladesh, Country reports". Hybrid Rice Development in Asia: Assessment of Limitation and Potential, Proceeding of Expert Consultation organized by The Regional Office for Asia and the Pacific of the Food and Agriculture Organization of the United Nations (FAORAP) And the Asia Pacific Seed Association (APSA) 2-3 July 2014. 
[19] M. Akhter, M. Riaz, M. Sabar, Z. Haider, and T. Latif (2004). "Hybrid rice development in Pakistan. Country reports". Hybrid Rice Development in Asia: Assessment of Limitation and Potential, Proceeding of Expert Consultation organized by The Regional Office for Asia and the Pacificof the Food and Agriculture Organization of the United Nations (FAORAP) And the Asia Pacific Seed Association (APSA) 2-3 July 2014.
[20] K. JothiSivagnanam,; Spread of New Varieties of Hybrid Rice and its Impact on the Overall Production and Productivity in Tamil Nadu, Agro Economic Research Centre University of Madras, Chennai 600005, AERC Research Study No: 153; 2014. 